\title{
User Defined Accounting Model
}

\author{
Charles Stivason, Marshall University, USA \\ Donald Hicks, Retired \\ Gary Saunders, Marshall University, USA
}

\begin{abstract}
At the heart of the free market system is the ability of the "Market" to determine what goods and services need to be produced and the appropriate allocation of resources to produce them in the most efficient and effective manner. Many believe that the current financial reporting model has not facilitated the achievement of this goal as fully as possible. A few ruling bodies have determined what information that is reported to investors and perhaps it is time to change this model and allow the market (individual users) to determine what financial information is most appropriate for investors, creditors and other external decision makers. With the improvements in technology, society may be able to create a User Defined Accounting Model (UDAM) that will allow investors to make better informed decisions in a timelier manner. The current financial reporting model, GAAP, requires companies to report information in one format which contains highly aggregated information that does not adequately address the predictive value of the information. Some users may believe that market value or replacement cost may be a more useful measure of the company's future value than historical cost. The current system aggregates the information at the firm level using primarily historical cost and then only forwards the results of this aggregation to users. An improvement would be to allow users to determine which measure they would like to employ. This paper proposes a model that allows users to access the primary measures instead of obtaining only aggregated, secondary data, and to compile financial statements in any format they desire.
\end{abstract}

Keywords: Accounting, Database, Model, Financial Accounting, Relational, Reporting, Transactions, User.

\section{INTRODUCTION}

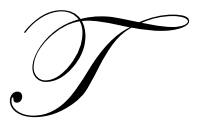

he first Statement of Financial Accounting Concepts asserts that financial statements should provide information that is useful to external decision-makers who are making investment and credit decision about the entity. Financial statements should be useful to those decision-makers and, who determines what is useful to a particular user is a major deficiency with the current financial accounting model/system. Until now, a few centralized ruling bodies have determined what information that is reported to investors. There are many factors that can affect the usefulness of information for external decision-makers and it is time to change the current model and allow the individual users to determine what financial information is most appropriate for their decision models.

This paper proposes that the current financial accounting reporting model does not provide the best financial information for external users to make investment and credit decisions and that a better model/system can be developed. The current model provides a unique reporting model for each reporting entity based on the choices made, from a selection of alternatives depending on the events being reported the reporting entity, for preparing general purpose financial statements. However, with certain exceptions by users with authority to demand (for example, lending institutions can require certain information, and the taxing authorities specify how information is to be prepared for them), individual users have no direct choice in determining what financial information is reported. Why shouldn't investors and other potential users of a company's financial information have the same ability to specify the specific information they require and not have to struggle to adapt the standard reported statements to their unique needs? 
Regulatory bodies, such as the Committee on Accounting Procedure, Accounting Principles Board, Financial Accounting Standards Board and the Public Committee Accounting Oversight Board have attempted to establish regulations which would result in optimal financial statements for user needs. However, different users have different information needs because their environments, decision criteria, decisions, or other criteria, are different. It should not be expected that one set of highly aggregated data can satisfy the decision-making needs of many different users. Accounting researchers agree that a single user of financial statements may have different data needs depending on the specific decision for which the data are to be used (e.g. Gjedsdal, 1981; Gaa, 1986; and others) and Watts and Zimmerman (1979) have shown that theoretical support can exist for any proposed model.

The intent of any model should be to satisfy user needs and the users are the ones who can best select the data that meets their needs. Therefore, the user should be allowed to select different data items in the same reporting period for the same reporting entity. Leftwich (1983) has shown that when users have the capability of selecting financial reporting methods, they choose a variety of approaches depending on their perceived needs.

A second concern with the present reporting model is the timeliness of the information. Traditional financial statements are backward looking and they lack timeliness because they are typically issued some months after the relevant period. However, users of the financial statements make decisions on a continuous basis and would be better served with more timely information.

\section{THE NEED FOR A NEW ACCOUNTING MODEL}

In order for users to select financial reporting methods most useful to them, they must have a set of data available which allows them a high degree of flexibility. In other words the user needs set of raw, relatively unaggregated data instead of reports with highly aggregated data, according to some established format, which masks the subtleties of the data. Such an available data set would constitute database reporting, or a User Defined Accounting Model (UDAM), which many people believe is the future of financial reporting.

Former Chief Accountant of the SEC John C. Burton said in 1984 that "By the turn of the century, as a result of the new information technology, it is highly likely that database reporting will replace accounting as we know it today both for internal and external purposes." [Burton, 1984] The end of that century has passed and the outdated model is still alive and well. Three years later J. Michael Cook, Chairman of Deloitte Haskins \& Sells, said "I can see the situation where the small-business owner would have an electronic hookup with his primary creditors, and the information they would need to monitor the operation of the business would be continuous and transmitted electronically." [Cook, 1987, quoted in Leepson, 1987]

In its purest form database reporting would mean that firms allow unrestricted access to their databases. However, the possibility of allowing "unrestricted" access appears to be remote and this section describes a databasereporting approach, which falls short of the completely unrestricted access format. The approach assumes the existence of some data in the database that will be considered propriety and that will not be disclosed. The undisclosed data could be of many types, confidential material, too costly to maintain, etc. Therefore, the new approach calls for disclosure of a subset of all of the possible data.

The committee on Foundations of Accounting Measurement (AAA, 1971a) looked at the adequacy the conventional accounting model in satisfying decision-makers needs. One area of prime importance to this committee was the distinction between primary measures and secondary measures. A primary measure is a number that is generated directly by quantifying the property of an object. A secondary measure is a number that is derived indirectly by an algebraic transformation of a set on numbers that are direct measures of some objects or their attributes. The committee determined that "the need to report simultaneously to many users of an accounting system will require output consisting largely of primary measures, with aggregation occurring mostly at the time of decision making." (AAA, 1971a, Page no 19.) The traditional model only reports highly aggregated secondary measures to the users, or decision-makers, which makes, according to the above, substantially irrelevant to the decision maker. 
This lack of primary measures is a major problem with the conventional accounting model. At the time of recording an event in the traditional accounting model a secondary measure, perhaps dollar amounts, is used to initially record the event while primary measures are readily available. The system can easily be modified to record the primary measures as well as the secondary measure as these primary measures may be more relevant to a decision maker. Another problem with the traditional accounting system is that many of the secondary measures, such as depreciation and inventory valuation, are quite arbitrary and do not improve the economic decision-making. In some cases these secondary measures may actually detract from good decision making. Different, more relevant, secondary measures should be available to the decision maker if the primary measures are provided.

Another committee (AAA, 1971b ) dealt with non-financial measures of effectiveness and found that with the conventional accounting model data is frequently too highly aggregated. The committee felt that "long-run profits are probably the primary objective of most business firms, the contribution of the firm's current activities to long-run profits may be inadequately measured by traditional financial statements." (AAA, 1971b, Page no 181.)

Many believe that the conventional accounting model is too restricted in that it typically records events in secondary measures while they should be recorded in their primary measures to allow for different performance measures depending on the users needs. Additionally, the classification of events appears to be too arbitrary and that information of value to decision makers is being lost. Information should be stored in primary measures and then have transformations performed on them dependent on the users needs thus the aggregation process will depend on the users view. There is also a clear need to expand the accounting system to contain information other than the historical exchange-based data such as market value or replacement cost. This is done some now, e.g. some investments, but more is possible and the valuation choice currently rests with the firm. The relational model will answer these perceived deficiencies.

\section{ALTERNATIVE MODELS}

The relational database approach was developed to assist in more fully exploring the usefulness of accounting data it focuses on the multidimensionality of the accounting data. Since different users of accounting data have different analytical objectives the data should not be in a one-dimensional single unit of measurement. Additional primary data measures can typically be captured wit the original data, often with a negligible cost, and made available to the user. Including these primary measures and making then available, addresses one of the major criticisms of the conventional accounting model. The 'events' used in this approach are the same events recorded in the traditional model. One of the major benefits of the relational approach is the use of multiple views (measures) of the accounting data as needed by the various users of the accounting data.

A number of attempts have been made to overcome the problems and limitations of the conventional accounting model. The majority of the attempts have used an events approach based on Sorter's (1969) events accounting theory. This 'events' approach has been integrated with, hierarchical, network and relational database models. Unfortunately these attempts have not used a true 'events' approach as described by Sorter (1969). These approaches have continued to use a historical dollar value approach with additional disclosure for selected users.

Haseman and Whinston (1976) attempted to use a hierarchical accounting model. Their system appears to be a step towards corporate database integration. Their example shows integration between production data and accounting data, but the accounting data still uses the value-based theory. In this case the multidimensional aspect comes from the use of interdepartmental data. They separate employee production into four files. One file contains the hours worked, parts produced, number of parts produced and number of defective parts. A second file contains the employee number, name and address. A third file contains information on the value added for each part and the average number of defects. The last file contains the summary information on the employee wages, all of which are primary measures.

Lieberman, and Whinston (1975) also attempted to devise a multidimensional accounting system. The authors focused on increasing the amount of information available and not moving from the conventional accounting model and its value-based theory to the events based theory. The authors state "in a typical accounting system there 
would be numerous event-types (as a minimum, there would be one event-type corresponding to each of the ledger accounts)." (Page no. 249) This statement clearly shows that they are relying on the ledger to base their system. American Accounting Association's $(1969,1971)$ research committees have pointed out the use of the ledger as a problem with the conventional accounting model.

McCarthy (1982) proposed the economic Resources Events and Agents (REA) accounting model as an answer to the some of the relevant problems with the conventional accounting system outlined in the prior section. Instead of recording an event with two offsetting entries for the same monetary value the model records the event using primary measures. Ijiri (1975) defines economic resources as objects, which are (1) scarce and have utility and (2) under the control of an enterprise. The stock of resources in the REA model corresponds to the assets in the conventional accounting model. The flow of these resources corresponds to the revenue and expense in the traditional dual-accounting model. The economic events are the basis of the information in an accounting system according to Ijiri (1975) and Sorter (1969). Yu (1976) defines economic events as changes in resources from production, exchange, consumption, or distribution. (This is the heart of the REA model and the dual-accounting model. McCarthy (1982) states that "event descriptions would be maintained perpetually as base elements of the conceptual schema." (Page 562)

In the traditional accounting model an event is the catalyst to the recording of an journal entry debiting and crediting account balances with equal amounts. The REA model proposed by McCarthy has a duality associated with the event. The duality in the REA model is based on the idea of obtaining something of utility by exchanging something of utility. Thus for any decrement of a particular resource there should be a corresponding increment of another resource, but not necessarily within a particular entity. This concept is based on Ijiri (1975). Ijiri describes this duality as "the duality of an increment and a decrement comes from the perceived cause-and-effect relationship between a sacrifice (a decrement) and a benefit (an increment), namely the benefit cannot be obtained without the sacrifice." (Page no. 61)

The REA model could be used in conjunction with a relational database to store the primary measures and allow multiple users to view the data as their needs require. This would require a change in many firms accounting information system. Many firms have already adopted this schema in part by using SAP, ORACLE, PEOPLESOFT, etc. This software allows firms to store the primary measures needed by various internal users in their decision making and allowing them to view it in various formats, etc. as required. The adoption of the REA model for financial recording would facilitate the UDAM.

\section{DEVELOPMENT ISSUES}

Mr. Andrew Bartels, vice president, Electronic Commerce Research Leader, in an address to the Virginia Internet Technology Conference (2000) indicated that one of the future trends in the Internet community is to make more company information available to business partners. One of the key aspects of this change is the development of middleware that will allow external users to view a company's information without having to interface directly with the companies' backend database or legacy systems. Companies will also have some form of layered security at the server level to help safeguard sensitive data. This trend can be extended to the investors and allow for more timely financial information.

The internet provides the perfect tool for the UDAM system. According to the AICPA (2000) "more than $80 \%$ of major US public companies provide some type of financial disclosure on the Internet." (Page no. 1) A common reporting language, XBRL (eXtensible Business Reporting Language), is being developed to facilitate the delivery of the current financial statements. This may be an appropriate "middleware" for the UDAM. According to Barry Melancon, President and CEO of the AICPA (2000) "XBRL helps companies, analysts, investors and other audiences to make better informed financial and management decisions and to leverage the capabilities of the Internet to facilitate the exchange of financial information." (Page no. 1) These are underlying reasons for our UDAM distribution plan. 
Lawson Software indicated in a press release dated April 6, 2000 that "XBRL offers several key benefits such as technology independence, full interoperability, efficient preparation of financial statements and reliable extraction of financial information. Information is entered only once, allowing that same information to be rendered in any form, such as a printed financial statement, an HTML document for a company's Web site, an EDGAR filing document with the SEC, a raw XML file or other specialized reporting formats such as credit report or loan documents." (Page No.1) This type of software will allow the users to select the format of the information for their decision making needs. In the October 1, 2007 issue of Financial Week the SEC has approved some major initiatives with XBRL that should speed up adoption of XBRL.

The auditing profession would have to adapt its activities to serve a UDAM. There would be two critical points in such a reporting system where external verification would seem to be needed. The first is the subset of data available to the users. An external profession would be needed to attest to the fact that the all economic data is made available, and that the data accurately portray the events, which actually occurred and impacted the financial condition of the firm. Secondly, an attest function is required for the programs the intermediary uses to aggregate the data according to user specifications. A user would want some assurance that what was received was what was actually selected. Obviously, in order for the specified aggregation to be verified there would have to be an established correct method.

If this system were implemented, reporting methods would be selected by the person(s) desiring the information. Initially, therefore, there would be multiple aggregation methods used by various users to make decisions. How would this lead to a market selection of reporting standards? The capital market traded on the New York Stock Exchange will serve for an illustration. In this market a user may desire to maximize the present value of cash flows. In order to do this, a user requires a data set to project future cash flows from investments, and trades to maximize those expected future cash flows. A superior model for a particular user is therefore a model which outperforms other models in predicting future cash flows from investments for that user. The user can then select only the significant information needed for that model. Furthermore, the reporting system could react quickly to changes in the environment. Users would have available whatever information they needed to make decisions, and an external body would no longer have to concern itself with determining user needs, or specifying reporting standards to satisfy those needs. Firms would want to make the information available to potential investors or face the possibility that the users would invest in another firm that did publish the requested information.

An important question associated with maintaining a database to support UDAM is how much data should be submitted and stored on UDAM. There are two schemes for providing the data to support UDAM. In the first scheme the individual economic transactions can be processed at the firm's legacy system and only summary data can be transmitted to the UDAM. In the second scheme all of the transactions can be transmitted to UDAM where it will be further processed to support user queries. Under both schemes, the data would have to be converted into a standard format such as XBRL. Since both schemes have advantages, selecting among the two schemes is dependent on which of the two locations is better for processing the financial information needed to operate the system and how to transmit the data from the legacy system where the data originates to the UDAM server.

At the lowest level, every financial transaction generates at least one record. For example, a transaction involving the purchase of a fixed asset includes one record that should include the purchase date, the purchase price, the useful life, and the salvage value at the end of the asset at the end of the useful life. Since a UDAM should allow the users of the system to calculate the depreciation expense for the financial statements using various depreciation methods, there are some advantages with transmitting the entire record to UDAM. The more detailed information available in the system, the more flexible the system will be; the system will be better able to change to handle divergent user requests and environmental changes. Since the UDAM model will be geared to doing this type of processing, it may be more efficient to centralize all of the data processing at the UDAM server.

Despite these benefits, there is a major reason not to transmit the entire record. The more data stored at the UDAM sever, the greater the risk that sensitive information will become available to competitors. If all of the information is stored on UDAM and a competitor gains access to restricted data, the question of whom to blame arises. If only summary information is transmitted to UDAM and all of this information is available to the users of the system, then there is no question of blame. 
The alternative method is to have the data translated to the form needed by UDAM and then further processed to handle all of the different requests that UDAM will support. Using our example, the firm will provide summary data to UDAM showing the depreciation for each of possible methods. The system at each individual organization, for example, would have to be updated to support a all depreciation methods. If all of the records are transmitted and stored on UDAM, the system could calculate the depreciation as required. This may be necessary for some firms due to the size of their transaction files.

In addition to the accounting data, the database should contain additional useful information. For example, the status of research and development projects and the backlog of orders for products are key data items useful to many decision-makers. These can be stored in narrative format that allows the user easy access.

\section{SYSTEM SPECIFICATION}

The UDAM system will consist of a series of programs that operate the user/system interface menus and that respond to the user requests. Since the technology to handle this processing already exists, the limiting factor will not the technological difficulty of building the system but the amount of programming effort needed to develop the system. For example, to offer the user a choice on depreciation methods, the system will have to have modules to calculate depreciation expense and accumulated depreciation for Straight Line, Declining Balance, Sum of the Years Digits, and, if applicable, Usage. In addition, UDAM may have to support other, non-GAAP methods. If the system also offers the user the choice of using historic cost, replacement cost, and exit cost to value assets, the amount and the degree of complication of the programming needed to support the system has increased significantly. Each choice is relatively easy to program but the cumulative effort of developing such a system is significant.

UDAM should be user friendly. To accomplish this, the system should be menu driven to enhance user accessibility to the data. The system is, thus, able to give the users easy access to alternative methods from which to prepare the financial statements in the format that they desire. UDAM should have the capability to process the data using the specified accounting process desired by the user and to respond to the user request in 'Real-Time' -- such that the user can make an immediate decision. The user thus has the ability to prepare the financial statements using the accounting methods that he/she personally finds most relevant, useful, and meaningful. Despite that goal, there will probably be a limit to the number of alternatives from which the user can select. If the user desires the use of accounting principles not programmed into the system, and if the data is in the primary measures the user can download the required data and process it using their own software.

At the highest level, the user can decide whether the environmental assumptions currently used in developing accounting standards supports their needs. For example, the user can decide whether the monetary / measuring unit assumption is consistent for the decision-makers' needs. At the direction of the user, the system could prepare alternative financial statements using constant dollar instead of historic dollars. If the user did not believe the "going concern" assumption was valid, the system could prepare financial statements showing the disposal value of the entity. The system should provide options based on all of the relevant environmental assumptions made in accounting.

Not all users will find Generally Accepted Accounting Principles (GAAP) to be the best basis for preparing financial statements. The second level of choice would be between preparing financial statements using GAAP and alternative non-GAAP procedures. For example, the user may wish to have the funded status of pension liabilities presented on the Balance Sheet as a liability instead of only a portion of the liability recorded as Accrued / Prepaid Pension Costs. The system should be able to prepare financial statements using other relevant, non-GAAP accounting principles.

Even within GAAP, there are alternative acceptable ways of processing the same data. The third level of options would allow the user to select among alternative acceptable GAAP principles. For example, the user may select among the alternative procedures for valuing inventories, depreciating fixed assets, or whether to use full costing versus successful efforts to account for exploration costs for extractive industries. Other choices for the user might include selecting how to group inventory items for the Lower of Cost or Market valuation, whether to group all inventory items 
together, in groups of like items, or to consider each item individually.

\section{IMPLICATIONS}

There are several implications of such a reporting model. For one, firms would be divided between those large enough to have a database system and those not so large. This dichotomy is already occurring with FASB exempting smaller firms from some reporting requirements. Smaller firms could get around this exclusion by providing general ledger data coupled with sufficient information about accounting procedures. This effort is not without cost, and some smaller firms might not be willing, or able, to undertake the task.

Second, firms could charge for external reporting. This would not entirely relieve the company of reporting costs, but it would allow firms to recover part or all of those costs, and serve as a rationing factor for access to the data. The model does not intend to imply that the reporting entity would not bear any of the reporting costs. In many cases it would be to the firm's advantage to incur those costs [Jensen and Meckling, 1976], and database reporting may not alter that condition.

Third, the timeliness of the reports would be limited only by the interval between updates of the data subset made available. How frequently the data set would be updated would also be determined by market mechanisms. Companies seeking access to the capital market might update more frequently than those in conditions of financial stringency might, for example.

Fourth, auditing would have to be continuous in order to verify the data in the database. In many cases this would not be a significant change for many large accounting firms in the time they spend auditing major clients. However the expertise and type of work performed may be altered.

Fifth, since the user would make choices, both trivial and nontrivial, the risk associated with those choices would be borne by the user. This would not relieve auditors of all risk, however, as they would be at risk where they attest the database and aggregation program validity.

\section{Areas For Future Research}

There are also areas that need further consideration. Does acquiring external access to the data bases require standardized databases? Security of sensitive data must be provided. Will database reporting supplant the need for standardized financial statements, or supplement them? Would the implementation of database reporting make the FASB obsolete, or merely alter its role? Are enough of the information markets efficient to make database reporting effective? Many of these questions can only be answered after the system becomes operational.

Would market factors lead to implementation, or would such a massive disclosure system require external, perhaps governmental intervention? The FASB lacks the power; how about the SEC?

Presumably, firms that believe database reporting would allow them to attract capital would want to implement this type of system. Might their voluntary disclosure lead to a gradual evolution of database reporting? Users traditionally have a very small power base. Therefore it would seem unlikely that user demand could force the necessary disclosure unless it were in the interest of the reporting entity to disclose.

\section{SUMMARY AND CONCLUSIONS}

With diverse user needs for financial information, the only way to adequately serve those needs is to allow users choice in financial reporting. User selection implies that preparers must make available a set of data from which users can develop the reporting models they desire, or database reporting. This paper proposes such a model. The key factors are 1) a subset of the firm's data which is made available to outsiders; 2) the availability of other data, for instance current price lists; 3 ) middleware software which accesses the available data and has the capability of aggregating it according to user menu selections. 
Two necessary attest points exist. First, the data subset, and second the intermediary's response. For instance, if the customer requested reports using straight-line depreciation and the firm's life and salvage estimates, the intermediary's reports should incorporate that method.

If an information market that is efficient in the sense of publicly available information is assumed, the user-selected standards that performed best would set the standards by being impounded in prices of financial resources. Thus user needs are met. The risk of using alternative reporting models would be born by the users.

Database reporting would allow for market selection of accounting standards. This does not mean that the market must select a database-reporting model. Database reporting can be required, or voluntarily selected, or never implemented. If, however, it is implemented database reporting will result in market selection of accounting standards. Database reporting is technically possible now. When implemented, it will result in more timely information with which to make decisions regarding allocation of scarce resources. It would also significantly alter information production and the role of the accountant and auditor in producing financial information.

\section{AUTHOR INFORMATION}

Charles Stivason received his Ph.D. from Virginia Polytechnic Institute and State University, with a specialization in artificial intelligence. His teaching areas include Auditing and Accounting Information Systems. He worked in public accounting for eight years prior to obtaining his Ph.D. He is currently an assistant professor at Marshall University.

Donald Hicks is former Chair, Department of Accounting at Christopher Newport University. He earned a PhD at Michigan State University and is now retired.

Gary Saunders, DBA, CPA earned his doctorate at the University of Kentucky in 1977. He joined the faculty at Marshall University in 1990 and is currently Professor of Accountancy and Elizabeth McDowell Lewis Chair in the LCOB at Marshall. Dr. Saunders has published extensively and has authored two accounting simulation textbooks, a cost accounting textbook and a spreadsheet textbook. He operates Integrated Business Systems, a publishing company.

\section{REFERENCES}

1. AICPA, (2000). AICPA Leads Global XBRL Initiative To Facilitate The Exchange Of Financial Statements Across All Technologies. AICPA (April 6, 2000) Available: //aicpa.org/news/p040600.htm /10/20/00

2. American Accounting Association, (1969). "Report of Committee on Managerial Decision Models," The Accounting Review (Supplement 1969), pp 43-76.

3. American Accounting Association, (1971a)."Report on the Committee on Foundation of Accounting Measurement." The Accounting Review (Supplement 1971), pp. 1-48.

4. American Accounting Association, (1971b). "Report of the Committee on Non-Financial Measures of Effectiveness," The Accounting Review (Supplement 1971), pp 164-211.

5. Bartels, Andrew, (2000), Virginia Internet Technology Conference 2000, Williamsburg VA

6. "Dean Burton Urges Accountants to Embrace New Technologies," (1984). Deloitte Haskins \& Sells, The Week in Review (October 26, 1984), pp. 1-3.

7. Gaa, J. C., (1986). "User Primacy in Corporate Financial Reporting: A Social Contract Approach," The Accounting Review (July 1986), pp. 435-454.

8. Gjedsdal, F., (1981). "Accounting for Stewardship," Journal of Accounting Research, (Spring 1981), pp. 208-231.

9. Haseman, W.C, and A.B. Whinston, "Design of a Multi-dimensional Accounting System," The Accounting Review, January 1976, ppl. 65-79.

10. Ijri, Y., (1975). Theory of Accounting Measurement (American Accounting Association, 1975).

11. Jensen, M. C. and W. H. Meckling, (1976). "Theory of the Firm: Managerial Behavior, Agency Costs and Ownership Structure," Journal of Financial Economics (October 1976) pp. 305-360. 
12. Lawson, (2000). Lawson joins global committee to launch XBRL standards; New SPEC exchanges financial reports via the Internet. Lawson Software (April 6, 2000) Available:

//lawson.com/news/pressreleases/2000/4/xbrl.html /10/20/00

13. Leepson, Marc, (1987). "Taking off by the numbers; Accounting expands into many nontraditional areas," Nation's Business (August 1987) Vol. 75, p. 48.

14. Leftwich, R., (1983). "Accounting Information in Private Markets: Evidence from Private Lending Agreements," The Accounting Review (January 1983), pp. 23-41.

15. Lieberman, A.Z., and A.B. Whinston, "A Structuring of an Events-Accounting Information System,” The Accounting Review, April 1975, pp. 246-258.

16. McCarthy, W.E. (1982),"The REA Accounting Model: A Generalized Framework for Accounting Systems in a Shared Data Environment," The Accounting Review (July 1982), pp. 554-578.

17. Rummell, N. (2007) "SEC makes it EZ to groove with XBRL," Financial Week, October 1, 2007.

18. Sorter, G.H., (1969). "An `Events' Approach to Basic Accounting Theory," The Accounting Review (January 1969), pp. 35-49.

19. Yu, S. C. .1976. The Structure of Accounting Theory (The University Presses of Florida)

20. Watts, R. L. and J. L. Zimmerman, (1979). "The Demand for and Supply of Accounting Theories: The Market for Excuses," The Accounting Review (April 1979), pp. 273-301. 


\section{NOTES}

